\title{
Polyaniline nanofibers as a new gamma radiation stabilizer agent for PMMA
}

\author{
P. L. B. Araujo ${ }^{1}$, R. F. S. Santos ${ }^{2}$, E. S. Araujo ${ }^{*}$ \\ ${ }^{1}$ Laboratório de Produtos Naturais Bioativos, DQ/UFRPE, Av. Dom Manoel de Medeiros, s/n, 52171-900 Recife, \\ PE, Brazil \\ ${ }^{2}$ Laboratório de Polímeros, DEN/UFPE, Av. Prof. Luis Freire, 1000, 50.740-540, Recife, PE, Brazil
}

Received 8 February 2007; accepted in revised form 15 May 2007

\begin{abstract}
Polyanilines are reported to exhibit stabilizing effects in rubber mixtures submitted to gamma-irradiation and thermo-oxidative treatment. Such abilities may be explained by their action as radical scavengers. Since radical formation followed by main chain scission is a widely accepted mechanism for radiolytic degradation of PMMA, polyaniline is a promising additive for commercial plastics submitted to radiosterilization processing. In this work, we investigated the ability of polyaniline emeraldine salt nanofibers $(\mathrm{PANF}-\mathrm{HCl})$ in preventing radiation damage on PMMA matrix. Effects of gamma-irradiation on PMMA/PANF-HCl composites films were assessed by comparison of the variation of viscosityaverage molar mass $\left(M_{v}\right)$ of PMMA at $25 \mathrm{kGy}$ dose when compared to commercial PMMA films. Samples containing $0.15 \%$ PANF-HCl (wt/wt) retained $92 \%$ of the initial $M_{v}$ after irradiation while control sample presented $42 \%$ of $M_{v}$ retention. When exposed to 60-200 kGy doses, PANF-HCl embedded into PMMA matrix preserved their oxidation state but started to exhibit mild deprotonation. PANF-HCl nanofibers were characterized by Diffuse Reflection Infrared Fourier Transform Spectroscopy (DRIFTS) and Scanning Electronic Microscopy (SEM). PMMA/PANF-HCl composites films were characterized by SEM and UV-VIS spectroscopy.
\end{abstract}

Keywords: nanomaterials, polyaniline, PMMA, gamma-irradiation, stabilization

\section{Introduction}

Poly(methyl methacrylate) (PMMA) is a high transparent common polymer, presenting excellent mechanical and chemical properties [1]. PMMA is widely used for manufacturing of medical and dental supplies. Gamma irradiation is one of the most popular methods for sterilization of plastic medical devices, typically performed at $25 \mathrm{kGy}$ sterilization dose [2]. When exposed to gamma-irradiation, PMMA undergoes radiolytic degradation by the formation of radicals followed by main chain scission and subsequent loss of mechanical properties [3]. While many additives have been used to protect polymers from thermo and photo-oxidative degradation [4-6], very little information on addi- tives for radiolytic stabilization of PMMA has been published. In 1960, Charlesby observed that substances such as urea, di-m-toluylthiourea, aniline, 8-hidroxyquinoline and benzoquinone, in 10\% (wt/wt), acted as protective agents against PMMA degradation caused by gamma irradiation [7]. Kolninov and Kolesnikova [8] showed that N,N,N',N'tetramethyl-4, 4'-diaminodiphenyl methane (Am) inhibited radiation induced degradation in PMMA matrix. Aquino and Araujo reported radio-protective action of a common photo-oxidative stabilizer, HALS (Hindered Amine Light Stabilizer), in PMMA films [9] and test specimens [10]. Both HALS [11] and Am [8] additives are believed to interrupt oxidative propagation reaction by scav-

"Corresponding author, e-mail: elmo@ @esquisador.cnpq.br

(C) BME-PT and GTE 
enging of alkyl radicals. Substances presenting similar antioxidant activities are suitable candidates for radiostabilizing agents.

Polyanilines and other intrinsically conducting polymers (ICPs) present well-reported metal-like characteristics [12-16]. In addition, polyanilines exhibit antioxidant effect in rubber mixtures submitted to gamma-irradiation [17] and thermooxidative aging $[17,18]$. Some reports show ICPs as biocompatible [19-22], biodegradable [22] and radical scavengers $[23,24]$ as well. Those important characteristics turn ICPs into attractive targets for studies of radiostabilizing effects on PMMA matrix.

In this work, we report a novel application of a conducting polymer, polyaniline, as radio-protecting for a conventional radio-sterilizable polymer, PMMA. Nanofibers of $\mathrm{HCl}$ doped polyaniline (PANF-HCl) were used at low amounts $(0.15-$ $0.30 \%(\mathrm{wt} / \mathrm{wt})$ ) into physical mixtures with commercial PMMA. Effects of gamma-irradiation on viscosity-average molar mass of commercial PMMA and PMMA/PANF-HCl composite showed that nanostructured PANI is an efficient protective agent against structural damage caused by gamma radiation.

\section{Experimental}

Aniline monomer, ammonium peroxydisulfate APS, butanone, calcium chloride $\left(\mathrm{CaCl}_{2}\right)$, hydrochloric acid $(\mathrm{HCl})$, methylene chloride $\left(\mathrm{CH}_{2} \mathrm{Cl}_{2}\right)$ and sodium dodecylsulfate (SDS) were of analytical grade. Aniline was vacuum distilled prior to use. Butanone was dried with $\mathrm{CaCl}_{2}$ and distilled. Other chemicals and commercial PMMA (Acrigel, $100 \mathrm{~kg} / \mathrm{mol}$, RESARBRAS ACRILICOS, Brazil) were used as received.

$\mathrm{HCl}$ doped Polyaniline nanofibers (PANF-HCl) was synthesized through interfacial self-assembly polymerization according to Huang and Kaner [25], modified by the introduction of SDS as a surfactant agent [26]. Briefly, An (298 mg) and SDS (30 mg) were mixed with $\mathrm{CHCl}_{3}(10 \mathrm{ml})$ and placed in a $50 \mathrm{ml}$ beaker. $10 \mathrm{ml}$ of a $1 \mathrm{M} \mathrm{HCl}$ aqueous solution containing $182 \mathrm{mg}$ of APS was gently added dropwise to the $\mathrm{CHCl}_{3}$ solution, in order to prevent extensive mixing of the layers. The reaction was allowed to proceed overnight at room temperature. Precipitated material was filtered though a Hirsch funnel, washed with deionized distilled water and dried in a dissecator. Yields were around $1 \mathrm{mg}$ of PANI-HCl per $10 \mathrm{mg}$ of An reagent. PMMA/ PANF-HCl mixtures were made as previously described [26]. In short, PANF-HCl dispersions in butanone (up to $250 \mathrm{mg} / \mathrm{dl}$ ) were obtained after 5 to 10 min of sonication treatment of PANF-HCl powder mixed with this solvent, at room temperature (ultrasonic bath Quimis, $40 \mathrm{kHz}$ ). The obtained dispersions were combined to appropriate volume of a $6 \mathrm{~g} / \mathrm{dl}$ PMMA/butanone solution and sonicated for $1 \mathrm{~h}$ at the same previously described conditions. $0.1 \mathrm{~mm}$ in thickness films containing 0.15 and $0.30 \%$ (wt/wt) PANF-HCl were obtained by casting from resulting mixture solution on glass plates. For comparison, PMMA in butanone solutions were sonicated for $1 \mathrm{~h}$ and PMMA film was also obtained by casting these solutions.

PMMA films and composite films were irradiated at 25 and $60 \mathrm{kGy}$ dose in a gammacell irradiator $\left({ }^{60} \mathrm{Co}\right)$ at $3.84 \mathrm{kGy} / \mathrm{h}$ dose rate.

Scanning Electronic Microscopy (SEM, JEOL 6360) characterization of PANF-HCl, PMMA and PMMA/PANF-HCl was performed on gold-coated samples. Films thickness was measured by SEM on cross-section view of cryofractured samples. Diffuse Reflection Infrared Fourier Transform Spectroscopy (DRIFTS) characterization was obtained from crushed neat PANF-HCl powder placed on patches. Spectrum was performed in an ABB spectrophotometer using a FTLA 2000-100 accessory, with 300 scans, over a $4000-400 \mathrm{~cm}^{-1}$ region and a $4 \mathrm{~cm}^{-1}$ resolution. UV-Vis characterization of PMMA and PMMA/PANF-HCl films was done in a Perkin-Elmer spectrophotometer (Lambda-6). Viscosity-average molar mass $\left(M_{v}\right)$ of PMMA and PMMA/PANF- $\mathrm{HCl}$ samples was determined with an Ostwald viscometer at $25^{\circ} \mathrm{C}$ using $0.3-3.8 \mathrm{~g} / \mathrm{dl}$ butanone solutions through Mark-Houwink's equation: $[\eta]=K M_{v}{ }^{a}$, where $[\eta]-$ intrinsic viscosity, $K=6.8 \cdot 10^{-5} \mathrm{dl} / \mathrm{g}, a=0.72$ [27].

\section{Results and discussion}

Fine dark green powder of $\mathrm{HCl}$ Doped Polyaniline was obtained through an interfacial polymerization method in presence of SDS surfactant. SEM images of the final reaction product show fibrillar or rodtype nanostructures, with diameters ranging from 100 to $150 \mathrm{~nm}$ (Figures 1a and 1b). In the presence of SDS, PANF-HCl were thicker than those made in the absence of this surfactant [26]. Such charac- 

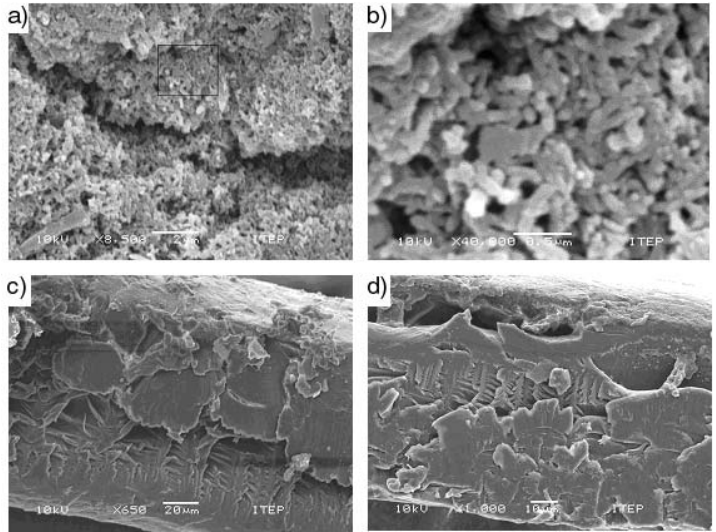

Figure 1. SEM images of: uncrushed PANF-HCl powder shows firmly packed aggregates of fibers or rods (a); higher magnification image of the region delimited by the square on Figure 1a (b); crosssectional view of non-irradiated cryofractured PMMA/PANF-HCl film (0.3\% (wt/wt)) (c) and neat PMMA film (d)

teristic may be desirable to ease the breaking up of the entanglements and to achieve a more homogeneous composite. Cross-section views of non-irradiated PMMA/PANF-HCl $\quad(0.3 \% \quad(\mathrm{wt} / \mathrm{wt}))$ (Figure 1c) and PMMA (Figure 1d) did not show any differences, probably due to the low PANF$\mathrm{HCl}$ loads used in this work.

DRIFTS characterization of PANF-HCl exhibits bands at $1620 \mathrm{~cm}^{-1}$ attributed to $\mathrm{C}=\mathrm{N}$ and $\mathrm{C}=\mathrm{C}$ stretching of the quinoid diimine unit. $\mathrm{C}-\mathrm{C}$ aromatic ring stretching of the benzenoid diamine unit appears at $1526 \mathrm{~cm}^{-1}$ and secondary aromatic amino group $\mathrm{C}-\mathrm{N}$ stretching vibrations are shown at $1355 \mathrm{~cm}^{-1}$. Each one of these bands is shifted approximately $60 \mathrm{~cm}^{-1}$ to higher wavenumber when compared to previous data obtained from $\mathrm{HCl}$ doped PANI by conventional FTIR method $[28,29]$. However, the presence of $\sim 1600$ and $\sim 1500 \mathrm{~cm}^{-1}$ bands implies the presence of amine and imine units in the molecular structure of PANF-HCl. Based on previous reports, the absorption intensity ratio of these two bands is an indicative of the oxidation state of the polymer [28, 30], as shown in the Equation (1):

$R=\frac{I_{1620}}{I_{1526}}$

From absorption intensity measured in DRIFTS data, $R$ is equal to 1.05 . This value identifies the emeraldine oxidation state of polyanilines [30]. Figure 2 shows the diffuse reflection IR spectra of PANF-HCl powder.

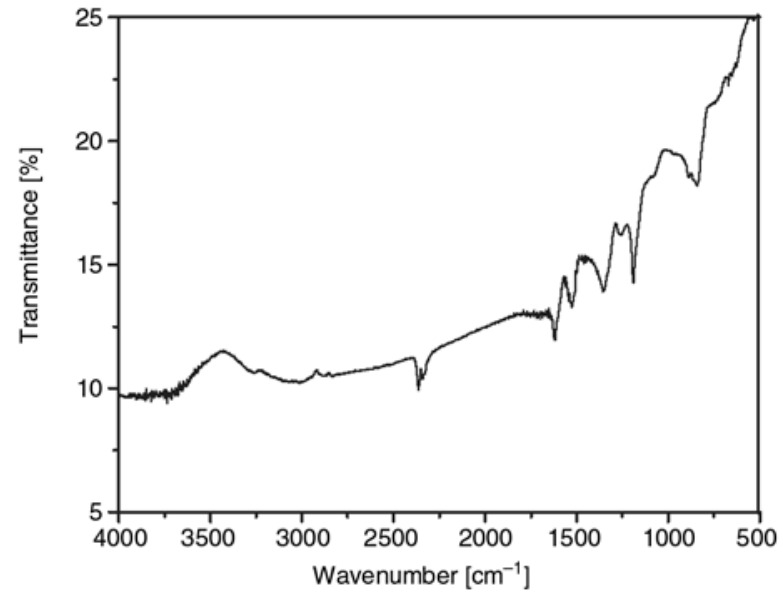

Figure 2. Diffuse reflection IR spectrum of neat PANF-HCl

Table 1. Variation of relative molar mass $\left(M_{v} / M_{v_{0}}\right)$ and protection index $P[\%]$ on irradiated polymeric system: PMMA + additive

\begin{tabular}{|c|c|c|c|}
\hline \multicolumn{4}{|c|}{ a) PANF-HCl composite films irradiated at $25 \mathrm{kGy}$ dose ${ }^{1}$} \\
\hline $\begin{array}{l}\text { PANF-HCl } \\
{[\%(w t / w t)]}\end{array}$ & $\begin{array}{c}\mathrm{M}_{\mathrm{v}_{\mathbf{0}}} \cdot \mathbf{1 0 ^ { - 3 }} \\
{[\mathrm{g} / \mathrm{mol}]}\end{array}$ & $\begin{array}{c}\mathbf{M}_{\mathbf{v}} / \mathbf{M}_{\mathbf{v}_{0}} \\
{[\%]}\end{array}$ & $\begin{array}{c}\mathbf{P} \\
{[\%]}\end{array}$ \\
\hline 0.15 & 90 & 92 & 93 \\
\hline 0.30 & 86 & 48 & 22 \\
\hline Control & 98 & 42 & - \\
\hline
\end{tabular}

b) HALS additivated PMMA films irradiated at $30 \mathrm{kGy}$ dose $^{2}$

\begin{tabular}{|c|c|c|c|c|}
\hline HALS type & $\begin{array}{c}\text { Additive } \\
{[\%(w t / w t)]}\end{array}$ & $\begin{array}{c}M_{\mathrm{v}_{0}} \cdot 10^{-3} \\
{[\mathrm{~g} / \mathrm{mol}]}\end{array}$ & $\begin{array}{c}\mathbf{M}_{\mathrm{v}} / \mathbf{M}_{\mathbf{v}_{0}} \\
{[\%]}\end{array}$ & $\begin{array}{c}\mathbf{P} \\
{[\%]}\end{array}$ \\
\hline \multirow{2}{*}{ TINUVIN $622^{\circledR 3}$} & 0.30 & 137 & 96 & 70 \\
\hline & 0.60 & 144 & 96 & 68 \\
\hline \multicolumn{2}{|c|}{ Control } & 155 & 87 & - \\
\hline
\end{tabular}

${ }^{1}$ This work, ${ }^{2}$ Reference [31], ${ }^{3}$ Reference [9]

PMMA/PANF-HCl composite films prepared as previously mentioned were approximately $0.1 \mathrm{~mm}$ in thickness, stiff, slightly green, transparent and visually homogeneous. In order to assess possible radiostabilizing effects of PANF- $\mathrm{HCl}$ on PMMA matrix, films containing 0.15 and $0.30 \%$ PANF$\mathrm{HCl}$ (wt/wt) were submitted to gamma irradiation at $25 \mathrm{kGy}$ dose. Variation on viscosity-average molar mass before $\left(M_{v_{0}}\right)$ and after irradiation $\left(M_{v}\right)$ showed that PANF-HCl containing samples underwent less degradation than control sample. Nevertheless, radio-protective actions decreased markedly when PANF- $\mathrm{HCl}$ concentrations increased from $0.15 \%$ to $0.30 \%$ (wt/wt) (Table 1). Radio-protective action of PANF-HCl can be seeing by comparison of $\alpha$ value (Equation 2), i. e. the number of main chain scissions per original molecule after irradiation: 
$\alpha=\frac{M_{v_{0}}}{M_{v}}-1$

were $M_{v_{0}}$ is the molar mass of non-irradiated polymer and $M_{v}$ is the molar mass after irradiation. From these values is possible to calculate the inhibition factor, $P[\%]$ (Equation 3), which indicates the reduction in yield of chain scissions in PMMA macromolecules containing PANF-HCl into polymer system:

$P[\%]=\frac{\alpha_{c}-\alpha_{a}}{\alpha_{c}} \cdot 100$

where $\alpha_{c}$ is the number of main chain scissions per original molecule in control samples and $\alpha_{a}$ in a given additivated sample, both irradiated at the same dose.

Composite containing $0.15 \%$ PANF-HCl (wt/wt) retained $92 \%$ of its initial molar mass after irradiation while control sample presented $42 \%$ of retention. PMMA/0.30\% PANF-HCl composite films showed $M_{v} / M_{v_{0}}$ ratio near to control value. In this case, PANF-HCl overload had an adverse effect on PMMA radioprotection. An excess amount of additive may act as an impurity that antagonizes the beneficial effect of the additive itself. The same phenomena could be observed when a type HALS additive, TINUVIN $622^{\circledR}$ [9], referred in the original work as $D$ type, was used as radioprotective agent for PMMA in concentration higher than the optimum concentration of $0.30 \%$ [31] (Table 1b). $P[\%]$ values for PMMA/PANF-HCl $(0.15 \%$ $(\mathrm{wt} / \mathrm{wt}))$ and PMMA/HALS $(0.30 \%$ and $0.60 \%$ (wt/wt)) films show again higher protective action of PANF-HCl when compared to TINUVIN $622^{\circledR}$, $93 \%$ and $70 \%$ and $68 \%$, respectively (Table $1 \mathrm{a}$ and 1b). It is important to notice that PMMA control sample presented in the results of Table $1 \mathrm{~b}$ was initially more resistant to radiation damage than the control sample used in this work (Table 1a).

PMMA/0.15\% PANF-HCl composite films were irradiated at 60 to $200 \mathrm{kGy}$ doses in order to verify possible alterations on PANF-HCl spectroscopic response on doses higher than the standard sterilization dose. UV-Vis absorption spectra of irradiated and non-irradiated composites are shown in Figure 3. PANF-HCl composite films showed three absorption bands at $\sim 365, \sim 420$ and $800-850 \mathrm{~nm}$ wavelength. These bands are typical of protonated form of polyaniline in the emeraldine oxidation

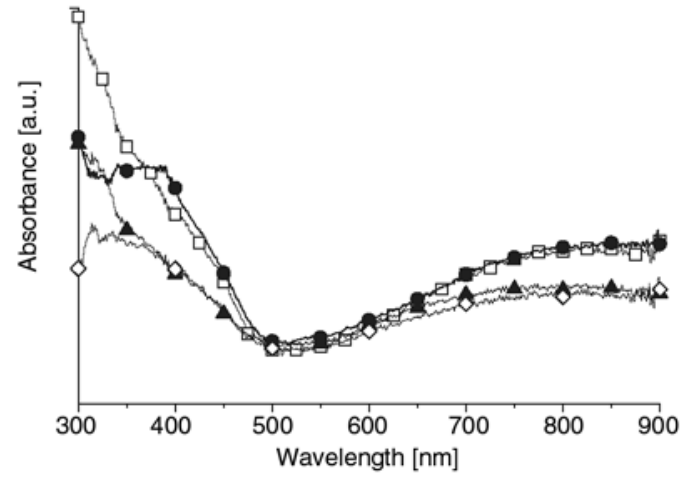

Figure 3. UV-Vis spectra. PMMA/PANF-HCl $(0.15 \%$ (wt/wt)) composites films normalized by thickness and respective spectra of neat PMMA films. Non-irradiated (-•-) and irradiated at 60 kGy (-口-), $100 \mathrm{kGy}(-\mathbf{\Delta -})$ and $200 \mathrm{kGy}$ $(-\diamond-)$

state. The first absorption band is assigned to a $\pi-\pi^{*}$ transition of the benzenoid ring and the other two bands are associated with the polaron transitions [32]. The free carrier tail exhibited in the red/NIR region of these spectra is also observed when polyaniline doped with $d, l$-camphorsulfonic acid is exposed to secondary dopant [33]. UV-vis of dispersions of polyaniline nanoparticles prepared in the presence of SDS showed similar feature [34]. The occurrence of carrier tail is attributed to the expansion of the molecular coil of polyanilines induced by secondary dopants. This effect persists even in blends of polyaniline with common polymers [33]. Bands around 340 and $390 \mathrm{~nm}$ are probably from additives present on commercial PMMA. These bands markedly decrease in irradiated neat films (data not shown).

After irradiation at $60 \mathrm{kGy}$, polaron bands at $\sim 420 \mathrm{~nm}$ and $800-850 \mathrm{~nm}$ showed small decrease in intensity. This trend is confirmed by spectra of 100 and $200 \mathrm{kGy}$ irradiated composite films. In addition there was a small increasing of absorption around $650-750 \mathrm{~nm}$ when compared to 800 $850 \mathrm{~nm}$ bands. These data suggest that the irradiation initiated a process of deprotonation in PANF$\mathrm{HCl}$. Similar effects were reported to PMMA/ polyaniline blends subjected to heat treatment in temperatures above $100^{\circ} \mathrm{C}$ [35].

\section{Conclusions}

It can be stated that polyaniline nanofibers doped with $\mathrm{HCl}(\mathrm{PANF}-\mathrm{HCl})$, synthesized by the method described in this work, it is an effective protection 
agent against radiation damage on PMMA matrix, PMMA/0.15\% PANF-HCl composite film exhibited a inhibition factor of $93 \%$ at the sterilization dose of $25 \mathrm{kGy}$. When exposed to $60-200 \mathrm{kGy}$ doses, PANF-HCl embedded into the matrix preserved their oxidation state but started to exhibit mild deprotonation.

The radiostabilizing capacity of PANF- $\mathrm{HCl}$ has significant implications on the use of polymer composites as biomaterials. Considerable work remains to be done, in order to determinate and fully understand the mechanism of PANF-HCl protection on PMMA matrix.

\section{References}

[1] Chapiro A.: Radiation Chemistry of Polymeric Systems. John Wiley \& Sons, New York (1962).

[2] Woo L., Ling M. T. K., Ding S. Y., Westphal S. P.: Effect of ionizing radiation on the thermal oxidative stability of medical polymers. Thermochimica Acta, 324, 179-185 (1998).

[3] Guillet J.: Polymers photophysics and photochemistry. Cambridge University Press, New York (1987).

[4] Agnelli J. A. M.: Degradação de Estabilização de Polímeros. UFSCAR, São Paulo (1988).

[5] Gächter R., Müller H.: Plastics Additives Handbook. Hanser Publishers, Munich (1990).

[6] Smoliak L. Y., Prokopchuk N. R.: Estimation of parameters that correlate molecular structure of hindered amines with their stabilizing efficiency. Polymer Degradation and Stability, 82, 169-172 (2003).

[7] Charlesby A.: Atomic Radiation and Polymers. Pergamon Press, New York (1960).

[8] Kolninov O. V., Kolesnikova V. V.: ESR study of stable $\quad N, N, N^{\prime}, N^{\prime}$-tetramethyl-4,4'-diaminediphenylmethane radicals in solid solutions. High Energy Chemistry, 35, 328-334 (2001).

[9] Aquino K. A. S., Araujo E. S.: Uso de aditivos comerciais tipo $H A L S$ na estabilização radiolítica em filmes de PMMA nacional. Revista Brasileira de Pesquisa e Desenvolvimento, 6, 45-52 (2004).

[10] Aquino K. A. S., Araujo E. S.: Caracterização estrutural do poli(metacrilato de metila) nacional estável à radiação gama: espectroscopia, propriedades óticas e viscosimetria. Revista Brasileira de Pesquisa e Desenvolvimento, 6, 107-115 (2004).

[11] Mark H. F., Bikales N., Overberger C. G., Menges G.: Encyclopedia of Polymer Science and Engineering. John Wiley \& Sons, New York (1989).

[12] MacDiarmid A. G., Chiang J. C., Richter A. F., Somasiri N. L. D., Epstein A. J.: Conducting Polymers. Reidel, Dordrecht (1986).

[13] Cotevieille D., le Méhautè A., Challioui C., Mirabeau P., Demay J. N.: Industrial applications of polyaniline. Synthetic Metals, 101, 703-704 (1999).
[14] Pron A., Rannou P.: Processible conjugated polymers: from organic semiconductors to organic metals and superconductors. Progress in Polymer Science, 27, 135-190 (2002).

[15] Bäcklund T. G., Sandberg H. G. O., Österbacka R., Stubb H., Mäkelä H., Jussila S.: Towards all-polymer field-effect transistor with solution processable materials. Synthetic Metals, 148, 87-91 (2005).

[16] Reece D. A., Ralph S. F., Wallace G. G..: Metal transport studies on inherently conducting polymer membranes containing cyclodextrin dopants. Journal of Membrane Science, 249, 9-20 (2005).

[17] Ismail M. N., Ibrahim M. S., Abd El-Ghaffar M. A.: Polyaniline as an antioxidant and antirad in SBR vulcanizates. Polymer Degradation and Stability, 62, 337-341 (1998).

[18] Helaly F. M., Darwich W. M., El -Ghaffar A.: Effects of some polyaromatic amines on the properties of NR and SBR vulcanizates. Polymer Degradation and Stability, 64, 251-257 (1999).

[19] Schmidt, C. E., Shastri V. R., Vacanti J. P., Langer R.: Stimulation of neurite outgrowth using an electrically conducting polymer. Proceedings of the National Academy of Sciences of the United States of America, 94, 8948-8953 (1997).

[20] Garner B., Hodgson A. J., Wallace G. G., Underwood P. A.: Human endothelial cell attachment to and growth on polypirrole-heparin is vitronectin dependent. Journal of Materials Science: Materials in Medicine, 10, 19-27 (1999).

[21] Kamalesh S., Tan P., Wang J., Lee T., Kang E. T., Wang C. H.: Biocompatibility of electroactive polymers in tissues. Journal of Biomedical Materials Research, 52, 467-478 (2000).

[22] Rivers T. J., Hudson T. W., Schmidt C. E.: Synthesis of a novel, biodegradable electrically conducting polymer for biomedical applications. Advanced Functional Materials, 12, 33-37 (2002).

[23] Gizdavic-Nikolaidis M., Travas-Sejdic J., Kilmartin P. A., Bowmaker G. A., Cooney R. P.: Evaluation of antioxidant activity of aniline and polyaniline. Current Applied Physics, 4, 343-346 (2004).

[24] Gizdavic-Nikolaidis M., Travas-Sejdic J., Kilmartin P. A., Bowmaker G. A., Cooney R. P.: Conducting Polymers as free radical scavengers. Synthetic Metals, 140, 225-232 (2004).

[25] Huang J., Kaner R. B.: A general chemical route to polyaniline nanofibers. Journal of the American Chemical Society, 126, 851-855 (2004).

[26] Araujo P. L. B., Araujo E. S., Santos R. F. S., Pacheco A. P. L.: Synthesis and morphological characterization of PMMA/polyaniline nanofiber composites. Microelectronics Journal, 36, 1055-1057 (2005).

[27] Brandrup J., Immergut E. H.: Polymer Handbook. John Wiley \& Sons, New York, (1989).

[28] Abdiryim T., Xiao-Gang Z., Jamal R.: Comparative studies of solid state synthesized polyaniline doped with inorganic acids. Materials Chemistry and Physics, 90, 367-372 (2005). 
[29] Kulkarni M. V., Viswanath A. K., Marimuthu R., Seth T.: Spectroscopic, transport, and morphological studies of polyaniline doped with inorganic acids. Polymer Engineering and Science, 44, 1676-1681 (2004).

[30] Huang L-M., Wen T-C., Gopalan A.: Synthesis and characterization of soluble conducting poly (anilineco-2, 5-dimethoxyaniline). Materials Letters, 57, 1765-1774 (2003)

[31] Aquino, K. A. S. Estabilizaçao Radiolítica do Poli(metacrilato de metila) utilizando aditivos comerciais. Master Dissertation, Federal University of Pernambuco, Brazil, 2000.
[32] Stejskal J., Kratochvíl P., Radhakrishnan N.: Polyaniline Dispersions 2. UV-Vis absorption spectra. Synthetic Metals, 61, 225-231 (1993).

[33] MacDiarmid A. G., Epstein A. J.: The concept of secondary doping as applied to polyaniline. Synthetic Metals, 65, 103-116 (1994).

[34] Kim B-J., Oh S-G., Han M-G., Im S-S.: Synthesis and characterization of polyaniline nanoparticles in SDS micellar solutions. Synthetic Metals, 122, 297-304 (2001).

[35] Yang C. Y., Reghu M., Heeger A. J., Cao Y.: Thermal stability of polyanilines network in conduction polymer blends. Synthetic Metals, 79, 27-32 (1996). 